\title{
EVALUATION OF ZIPPER TEAR STRIP DESIGN STRUCTURE FOR PAPERBOARD PACKAGING
}

\author{
Josip Bota (D), Gorana Petković \\ University of Zagreb, Faculty of Graphic Arts, Zagreb, Croatia
}

\begin{abstract}
Zipper tear strips (ZTS) are the most common user friendly, tamper-proof, opening system for paperboard and corrugated cardboard packaging. The base of ZTS design structure has parallel partial cuts repeated in the direction of the desired tearing line. The height (strip-width) of the tab can vary same as the shape in the cut design structure. In order to collect the most common zipper tear structure data, parameters were measured from samples of paperboard packaging found in a frequent Croatian supermarket. The obtained data was used to define 8 types of samples which were together with 4 new samples tested on two mainly used paperboards (250 g/m $/ \mathrm{m}^{2} \mathrm{GC1}$ and $270 \mathrm{~g} / \mathrm{m}^{2} \mathrm{GC2}$ ). Three type of tests were conducted: pull test for maximal tearing force, compression test to measure the structural degradation of a packaging and manual tearing to test the ZTS opening functionality success rate in real-life handling conditions.

The results show that the $45^{\circ}$ angle is most functional option and should be combined with the wider $13 \mathrm{~mm}$ ZTS instead of the usual $10 \mathrm{~mm}$. Also, there is an indication that a $0,5 \mathrm{~mm}$ increase between cuts can slightly improve structural stability and when combined with the wider tab can attain an increased tear resistance while having the adequate opening functionality success rate.
\end{abstract}

Key words: Zipper tear strip, tamper-proof opening, paperboard packaging

\section{INTRODUCTION}

The zipper tear strip (ZTS) also known as a zipper, zipper tab, zipper pull tab, tear-strip, zip-strip is a tamper proof opening system for paperboard and corrugated cardboard packaging. The design consists of cut and uncut parts (connected portions - CP, nicks) (Kirwan, 2012; Yam, 2009). The main goal of this feature is to provide the packaging a one-time opening or unlocking system. It allows the consumer feedback that the packaging was sealed from when its packed.

Construction of the tearing design varies depending on the manufacturer and preferences. Figure 1 shows the most common design structures that also vary with the lengths and curvatures of the cutting lines.

a)

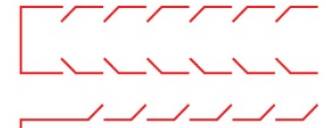

b)

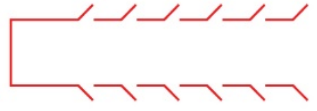

c)

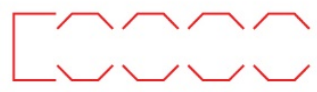

d)

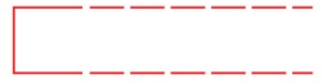

Figure 1: Types of zipper tear strips (ZTS)

Currently there are no standardized shapes or ratios in the paperboard industry, no guidelines, even research on this topic is scares. Just two available papers were found that tested five types of ZTS designs using the uncut parts and paperboard grain direction as variable (Nagasawa et al, 2017, 2018). One paper is written in Japanese which limits the comprehension using translation software's. As expected they found that the ZTS parallel to the machine direction of grain and the smaller uncut parts have a larger success rate than cross direction (CD) and longer uncut pars, respectively. In the research they used machine pulling without testing manual opening with participants. There are also two more papers from the same group of authors that were not accessible but the author stated that they are preparing an English version (Uehara et al, 2017, 2016). 
There are specialized book suggesting packaging designs with ZTS (Wybenga and Roth, 2013) and research that tests opening systems on people with limited range of motion and strength (Marks et al, 2012) but no specific guidelines. Australia even made guidelines for inclusive design for people with arthritis (Fain, 2018) but rarely there is a mention of this type of opening systems.

The issue with the ZTS is that the cutting across and around the paperboard and corrugated cardboard packaging decreases the structural stability and stackability. The strip needs to be durable enough not to collapse during transportation and handling, and have a $100 \%$ opening success rate. This is hard to achieve, especially in corrugated cardboard packaging, due to the variability in paper properties (cellulose grains, filament, humidity, etc.). Manufacturers sometimes sacrifice the rate of successful opening in favor of the mechanical properties so the package fulfills its role in product protection and as tamper proof evidence. The failure of opening is most commonly the result of delamination of paperboard and separation of layers in corrugated cardboards rarely because of breakage. This is mostly common when ZTS are narrow and not adequate to paperboard properties (tear resistance). One of the solutions used in the industry is gluing a plastic strip on the inside of the packaging that makes the ZTS multilayered and adds to the mechanical properties. This is mostly used in mailing packaging and envelopes. It requires an additional manufacturing process and makes the stripped part harder to recycle. Therefore, there is an interest to achieve maximal opening success rates with adequate mechanical properties produced with less manufacturing processes and keeping the recyclability of the packaging as a whole.

The goal of this paper is to test and evaluate the currently most commonly used ZTS designs on the market, using two standard packaging paperboards as a starting point to optimize this feature and suggest potential changes in design. The ZTS design and variables for this research was chosen for evaluating the currently most common type used in the Croatian market for paperboard packaging, shown in Figure 1 type a).

\section{METHODS}

\subsection{Materials}

The selected paperboards (DIN graded) are commonly used for packaging of food and drugs. Paperboard specifications, grades (according to DIN Standard 19303 "Paperboard - Terms and grades") sample variables and nomenclature are seen in Table 1. The paperboard was conditioned according to the ISO 187:1990 standard at temperature of $23^{\circ} \mathrm{C} \pm 1^{\circ} \mathrm{C}$ and humidity RV $50 \% \pm 2 \%$ before and during the testing.

Table 1: Paperboard samples nomenclature and specifications

\begin{tabular}{|c|c|c|c|c|c|c|c|c|}
\hline sample name & grammage & $d$ & $\alpha$ & w & ZTS shape & DIN grade & thickness & manufacturer \\
\hline Z43_d_a_w & $250 \mathrm{~g} / \mathrm{m}^{2}$ & \multirow{2}{*}{ 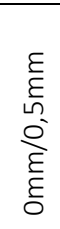 } & \multirow{2}{*}{ 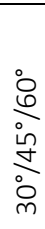 } & \multirow{2}{*}{ } & \multirow{2}{*}{ 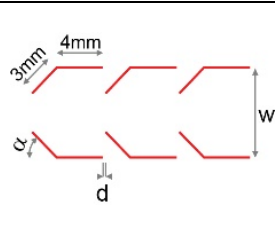 } & $\begin{array}{l}\text { GC1 (virgin } \\
\text { mechanical } \\
\text { pulp) }\end{array}$ & $0,41 \mathrm{~mm}$ & Ningbo $^{\circledR}$ \\
\hline T43_d_a_w & $270 \mathrm{~g} / \mathrm{m}^{2}$ & & & & & $\begin{array}{l}\text { GC2 (virgin } \\
\text { mechanical } \\
\text { pulp) }\end{array}$ & $0,46 \mathrm{~mm}$ & AllyKing ${ }^{\circledR}$ \\
\hline
\end{tabular}

\subsection{Samples}

The samples were made and named according to the variables presented in Table 1 . The cutting length of parallel and angled lines were defined at $4 \mathrm{~mm}$ and $3 \mathrm{~mm}$, respectively. These variables are fixed because over $90 \%$ of the ZTS found in frequent Croatian supermarket (with this type of strip design) had the specified lengths. All of the other variables $(w, d, \alpha)$ were defined according to the same findings with an exception of the $30^{\circ}$ angle. This angle was not found on any packaging with ZTS but was incorporated for this evaluation study. All samples were prepared using EngView Packaging and Display Designer Suite software and cut on a Zund M-800 flatbed cutter/plotter using a Z10 drag blade. The samples for the compression resistance and manual test were glued by using a water based dispersion of polyvinyl acetate with additives (Signokol ${ }^{\circledR}$ ) which is commonly used in the packaging line.

Two types of samples were prepared with the dimension specified in Table 2. The grain direction used in the samples was defined according to the most common position of the ZTS in relation to the design of the packaging. The panel ratio of the packaging simulation sample is defined as 4:1. This ratio has a reduced structural stability when compared with other shapes with a identical extent and are more often found on the supermarket shelfs (Bota et al, 2018). 


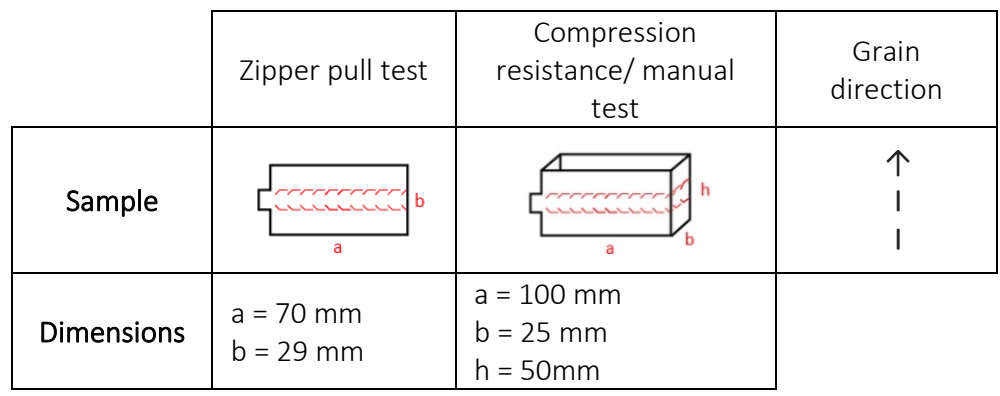

\subsection{Zipper pull test}

Measurement of the maximal force needed to tear off the ZTS was conducted on a modified digital force gauge, Mark-10 series 4, type M4-100. The sample was clamped to a 3D printed adapter to ensure a $45^{\circ}$ pulling direction that finishes under a $90^{\circ}$ angle (Figure 2). This simulates a typical angle of user handling. The pulling speed was $3,5 \mathrm{~mm} / \mathrm{sec}$ and the data was collected with the MESUR ${ }^{\mathrm{TM}}$ Lite data acquisition software. The results are show as Newton's (N).

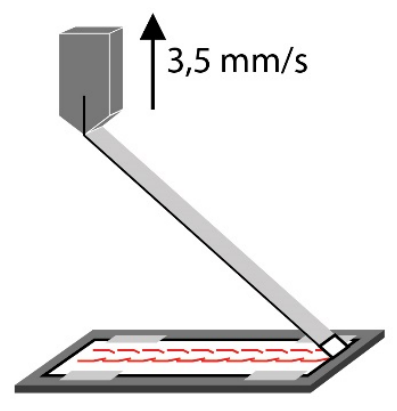

Figure 2: Zipper pull test

\subsection{Compression resistance test}

When the glue was completely dry (24h after gluing) the samples were tested for compression resistance using a modified Crush test instrument (Lorentzen \& Wettre Crush Tester) using Mode 1. The samples were pressed between two plates at a speed (movement of the upper plate) of $0,8 \mathrm{~mm} / \mathrm{sec}$ (Figure 3). The instrument records the maximum force in Newton's ( $N$ ) achieved till barreling occurs (shape deformation). Each shape and material was tested with six identical samples.

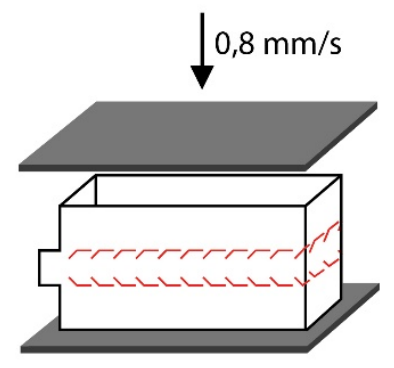

Figure 3: Compression resistance test

\subsection{Manual opening test}

After the compression resistance the test samples (six) were given to a user to tear of the ZTS. The user held the sample in the left hand and pinching the opening tab with his right hand thumb and index finger. The user was instructed to use the same grip, opening movement and speed for each sample. The handling 
and opening technique of the participant was not unusual. All twenty-four types of samples were handled by the same user.

\section{RESULTS AND DISCUSSION}

The goal of the results was to evaluate and compare the pull test, compression resistance and manual test (user handling and tearing of the ZTS) to provide conclusions about the optimal design and direction of further in-depth research on this topic.

\subsection{Zipper pull results and discussion}

Each sample had 9-12 tears depending on the angle and distance between the cuts. Every sample type was tested with 10 tests. For this study each maximum force of the pull test was collected. The ten results are presented as a mean with the maximum value in Figure 4.

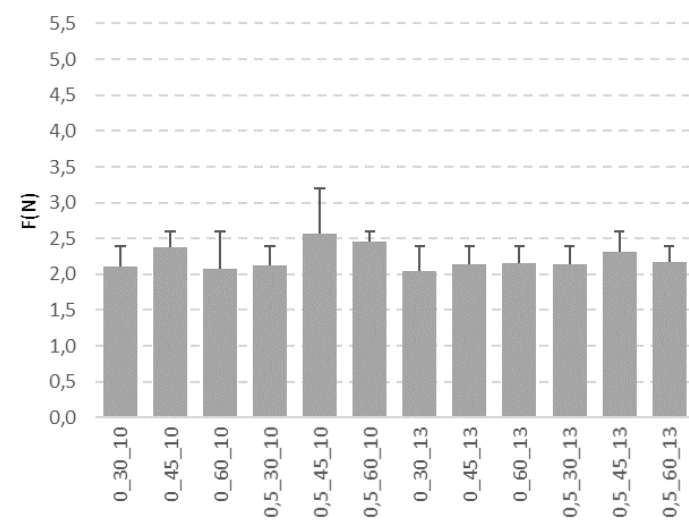

a) GC1 $250 \mathrm{~g} / \mathrm{m}^{2}$ paperboard

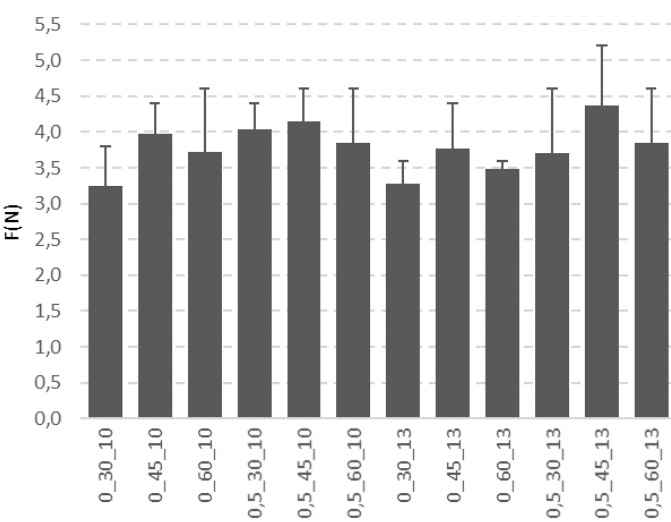

b) GC2 $270 \mathrm{~g} / \mathrm{m}^{2}$ paperboard

Figure 4: Zipper pull results for $250 \mathrm{~g} / \mathrm{m}^{2}$ and $270 \mathrm{~g} / \mathrm{m}^{2}$ paperboard samples

The results show that there are more prevalent pulling force variation in the $270 \mathrm{~g} / \mathrm{m}^{2}$ in comparison with the $250 \mathrm{~g} / \mathrm{m}^{2}$ paperboards. Most of the maximum forces in the $250 \mathrm{~g} / \mathrm{m}^{2}$ (Figure 4. a)) are in-between 2,4N and $2,6 \mathrm{~N}$ only the sample with the connected portion (CP) distance of $0,5 \mathrm{~mm}, 45^{\circ}$ angle and $10 \mathrm{~mm}$ ZTS width show an increase of pull resistance. Mostly the $45^{\circ}$ samples show increased pulling force resistance than other variables. Similar trend can be observed in the $270 \mathrm{~g} / \mathrm{m}^{2}$ (Figure 4. b)) results. It can be also seen that the samples with $60^{\circ}$ angled cuts show a larger pulling resistance than the $30^{\circ}$ samples. It can be augmented that those two samples have lower force resistance due to cuts more parallel /perpendicular to the grains but the $60^{\circ}$ has better results because the diagonal CP distance is larger due to the larger angle. An observation was made during conducting the test: Rarely both of the parallel CP tore at the same time during apparatus pulling. Mostly one side would tear off then the other partially rotating the ZTS in the process. According to Nagasawa and all (Nagasawa et al, 2017) this could be eliminated using Y shaped cuts (guiding routes).

\subsection{Compression resistance results and discussion}

Each variable variation was tested with six identical samples. The results are presented in Figure 5 as a mean of the results with standard deviation. Comparing the results with the control (without the ZTS) it can be seen an approximately $40 \%$ reduction in compression resistance. This is not a negligible decrease in structural stability. 


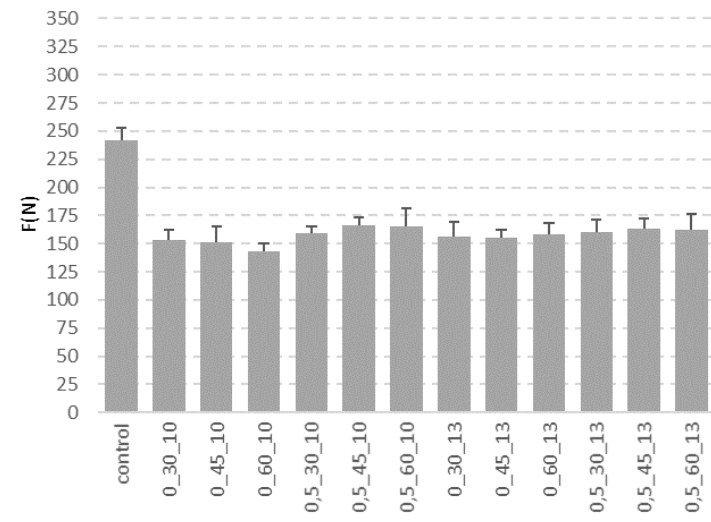

a) GC1 $250 \mathrm{~g} / \mathrm{m}^{2}$ paperboard

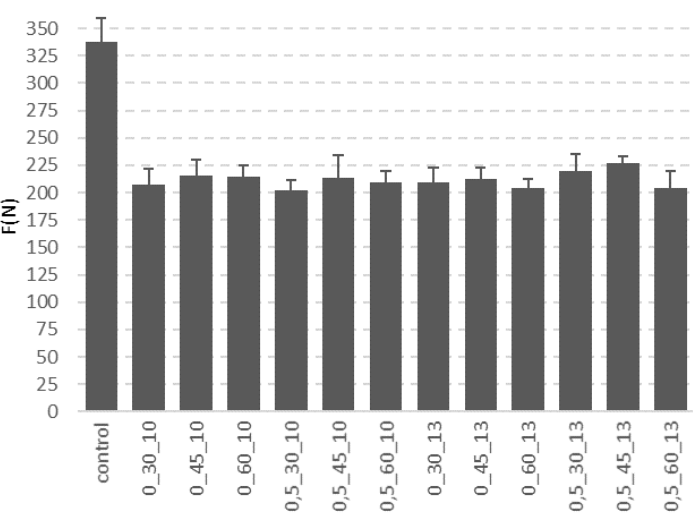

b) GC2 $270 \mathrm{~g} / \mathrm{m}^{2}$ paperboard

Figure 5: Compression resistance results for $250 \mathrm{~g} / \mathrm{m}^{2}$ and $270 \mathrm{~g} / \mathrm{m}^{2}$ paperboard samples

Similar to the pull test there is a more uniform set of results with the $250 \mathrm{~g} / \mathrm{m}^{2}$ paperboard samples (Figure 5. a)). Across the variables there can be observed a clearer trending line. The samples with the $0,5 \mathrm{~mm} \mathrm{CP}$ increase show a better compression resistance and again the $45^{\circ}$ ZTS show slightly increased resistance than $30^{\circ}$ and $60^{\circ}$ samples. This is more visible in the $270 \mathrm{~g} / \mathrm{m}^{2}$ paperboard samples (Figure 5 . b)). The horizontal and vertical distance in between cut lines are identical for samples with $45^{\circ}$ angle but in the $60^{\circ}$ the horizontal distance is less and there are more cut segments around the packaging simulation sample while in the $30^{\circ}$ angle there are less cut segments and the vertical distance is smaller. So if the structural stability is more dependent to the grain direction a $30^{\circ}$ cut cuts more grains than the $60^{\circ}$.

\subsection{Manual opening test results and discussion}

In order to truly test the ZTS design and variables a manual test was needed to find out the opening success rate of each sample. It's important to emphasize that all of the zipper pull tests were $100 \%$ successful and the samples were clamped to the base near the ZTS to reduce bending, but these are not real-life handling conditions. Figure 6 shows the success rate of manual opening of the samples that simulated packaging.

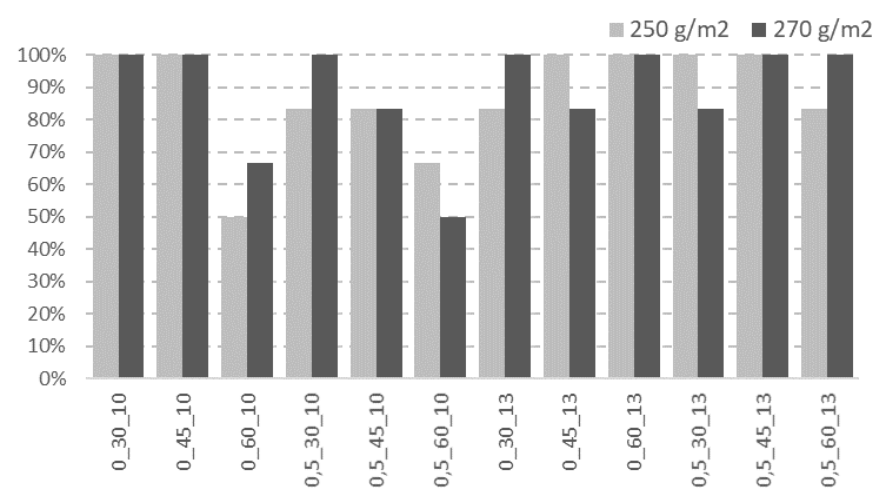

Figure 6: Opening success rate (\%) for $250 \mathrm{~g} / \mathrm{m}^{2}$ and $270 \mathrm{~g} / \mathrm{m}^{2}$ paperboard samples

This test was made on six samples and shows that not all samples have a 100\% success rate like in the controlled pull test. Only four samples achieved the targeted success rate for both types of paperboard. These samples were first tested to the compression resistance (similar to real-life conditions) and then submitted to "opening". There was no correlation found between the samples with higher compression resistance and successful opening. As expected (Nagasawa et al, 2018) most of the failed openings were a result of delamination and not because of the tearing of the strip (Figure 7). But this might be an issue with lighter paperboards for $10 \mathrm{~mm}$ wide ZTS strips. 

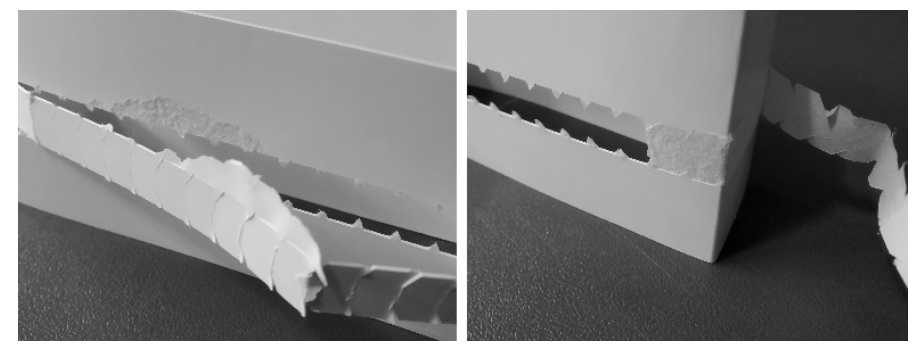

Figure 7: Delamination of the ZTS manual opening test

It is also observed that the wider $(13 \mathrm{~mm})$ ZTS have a higher success rate. This might be due to less rotation during handling of the strip which can lead the tearing force in the direction of a weak point in the lamination. Overall the sample that had a $45^{\circ}$ cut combined with the $0,5 \mathrm{~mm}$ CP distance for $10 \mathrm{~mm}$ ZTS with showed a higher pull resistance, a slighter increase in compression resistance but an $83 \%$ manual opening success rate. The same was not observed in the similar sample with wider $(13 \mathrm{~mm})$ ZTS. This should be investigated more thoroughly to better understand the anomaly.

\section{CONCLUSIONS}

This research was aimed to evaluate and investigate the difference between different ZTS variables together with the use of two common types of paperboards. For this research a new type of testing was developed using a digital force gauge. The results led to these conclusions:

- $\quad$ The ZTS decreases the compression resistance (stackability) of the packaging

- The $45^{\circ}$ angled cuts are an optimal solution and according this research the most functional design option

- Wider $(13 \mathrm{~mm})$ ZTS improves the successful opening rate for human handling

- There is an indication that $0,5 \mathrm{~mm}$ increase between cuts can slightly improve compression resistance

This research could be improved by preparing samples using a die-cut and increasing the number of samples and participants in the manual test. Also the ZTS should be further studied with other grammage of paperboard and with other types of fiber layer (recycled, non-bleached etc.) and compared with other types of designs to construct a model or find an optimal overall solution.

\section{REFERENCES}

[1] Bota, J., Jamnicki Hanzer, S., Banić, D., Brozović, M.,: "Compression resistance of small paperboard packaging shapes", Proceedings of $9^{\text {th }}$ International Symposium on Graphic Engineering and Design 2018, (GRID: Novi Sad, Serbia, 2018), pages 237-242.

[2] Fain, B.: "Food Packaging Design Accessibility Guidelines", URL: https://arthritisaustralia.com.au/wordpress/wp-content/uploads/2018/01/Food-Packaging-DesignAccessibility-Guidelines_Arthritis-Australia.pdf (last request: 2020-09-10).

[3] Kirwan, M.J.: "Handbook of Paper and Paperboard Packaging Technology" (Wiley-Blackwell, Hoboken NJ, USA, 2012), pages 268-277.

[4] Marks, M., Muoth, C., Goldhahn, J., Liebmann, A., Schreib, I., Schindele, S.F., Simmen, B.R., Vliet V.: "Packaging-A problem for patients with hand disorders? A cross-sectional study on the forces applied to packaging tear tabs.", Journal of Hand Therapy 25, 387-396, 2012. doi: 10.1016/j.jht.2012.04.003.

[5] Nagasawa, S., Uehara, M., Matsumoto, C.: "Effects of Guiding Routes and Grain Direction of Whiteclay-coated Paperboard on Tearing Characteristics of Zipper Pull Tab", Journal of the Japan Society for Technology of Plasticity, 2018. doi:10.9773/sosei.59.15.

[6] Nagasawa, S., Uehara, M., Matsumoto, C., Kambe, H., Jina, W.:" Estimation of stress and displacement around nick zone of zipper pull tab formed on paperboard", Proceedings of the JSME 2017 International Conference on Materials and Processing 2017, (JSME 2017: Los Angeles, California, 2017), pages 1-6. 
[7] Uehara, M., Nagasawa, S., Jina, W., Matumoto, C.: "Tearing characteristic of zipper pull tab of paperboard", The Proceedings of Conference of Hokuriku-Shinetsu Branch 2017, (Hokuriku-Shinets, Japan, 2017).

[8] Uehara, M., Nagasawa, S., Matumoto, C.: "Peeling behaviour of zipper tag and crack propagation on nicked zone", The Proceedings of Conference of Hokuriku-Shinetsu Branch 2016, (Hokuriku-Shinets, Japan, 2016).

[9] Wybenga, G.L., Roth, L: "The Packaging Designer's Book of Patterns, Packaging", (Wiley, Hoboken NJ, USA, 2012).

[10] Yam, K.L.: "Encyclopedia of Packaging Technology", (Wiley, Hoboken N.J., USA, 2009), pages 235236.

\section{(c) (1)}

(C) 2020 Authors. Published by the University of Novi Sad, Faculty of Technical Sciences, Department of Graphic Engineering and Design. This article is an open access article distributed under the terms and conditions of the Creative Commons Attribution license 3.0 Serbia (http://creativecommons.org/licenses/by/3.0/rs/). 